\title{
Detection of Beryllium in Human Lung Tissue Using Energy Dispersive X -ray Analysis
}

\author{
P. Ingram, K.J. Butnor, T.A. Sporn, V.L. Roggli \\ Duke University Medical Center, Department of Pathology, Durham, NC 27710
}

Chronic berylliosis is a hypersensitivity disorder characterized by non-necrotizing granulomatous inflammation of the lungs. Similar histopathologic features are seen in sarcoidosis. While a history of occupational exposure is usually apparent, detection of elevated levels of beryllium in lung tissue is helpful in establishing the diagnosis of chronic berylliosis.

Several techniques are employed for detection of beryllium in lung tissue, including electron energy loss spectroscopy [1], laser microprobe mass analysis [2], and secondary ion mass spectometry [3]. While highly sensitive, these modalities are relatively expensive and not widely available in a clinical setting. Over the past 30 years, conventional energy dispersive x-ray analysis (EDXA) has been used to detect elements of an atomic number $\geq$ that of fluorine $(Z=9)$ by excluding low-energy $x$-rays using a beryllium window. Newer atmospheric thin-window (ATW) EDXA detectors are theoretically capable of detecting lower atomic number elements such as beryllium $(Z=4)$. To our knowledge, detection of beryllium in human lung tissue using EDXA has not been reported [4].

We present a case of a 40 year-old female geologist with occupational exposure to beryllium. Tissue from open lung biopsy showed clusters of non-necrotizing granulomas with multinucleated giant cells (Figure 1). Polarizing microscopy demonstrated tiny birefringent particles in the granulomas.

A pure beryllium grid was mounted on a carbon disc and examined in a JEOLJSM 6400 scanning electron microscope equipped with a backscatter electron detector, a Gresham Sirius $30 \mathrm{~mm}^{2} \mathrm{x}$-ray detector, and a 4pi microanalyzer and pulse processor. With negative backscattered electron imaging (BEI), the beryllium grid appeared bright on a darker carbon background; EDXA yielded peaks for beryllium (not shown). A section of paraffinized lung tissue was mounted on a carbon stub, lightly rotary coated with carbon, and examined by secondary electron imaging (SEI), BEI, and EDXA. Areas with giant cells were readily identified by SEI (Figures 2 and 3A). With negative BEI, a few bright particles were seen in the cytoplasm of a giant cell (Figure 3B). EDXA of the particles yielded discrete peaks for beryllium (Figure 4A). Spectra from cytoplasm away from the particles (Figure 4B) yielded either lower peaks for beryllium or background levels.

The detection of beryllium in human lung tissue by EDXA is significant, in that this nondestructive technique allows for the separation of berylliosis from sarcoidosis using routine histologic seđions.

\section{References}

[1] D. Dinsdale et al., Exp. Mol. Pathol. 36 (1982) 396.

[2] W.J. Williams et al., Sarcoidosis 6 (1989) 111.

[3] R. Levi-Setti et al., Biol. Cell. 63 (1998) 77.

[4] P. Ingram et al., Biomedical Applications of Microprobe Analysis, Academic Press, San Diego, 1999. 


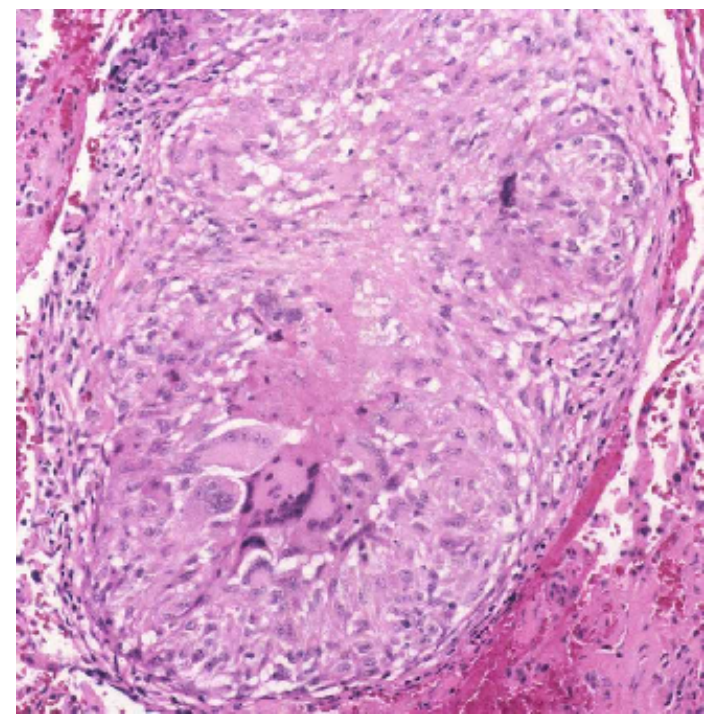

FIG. 1. Lung tissue with non-necrotizing granulomas (hematoxylin and eosin, original magnification x 200).
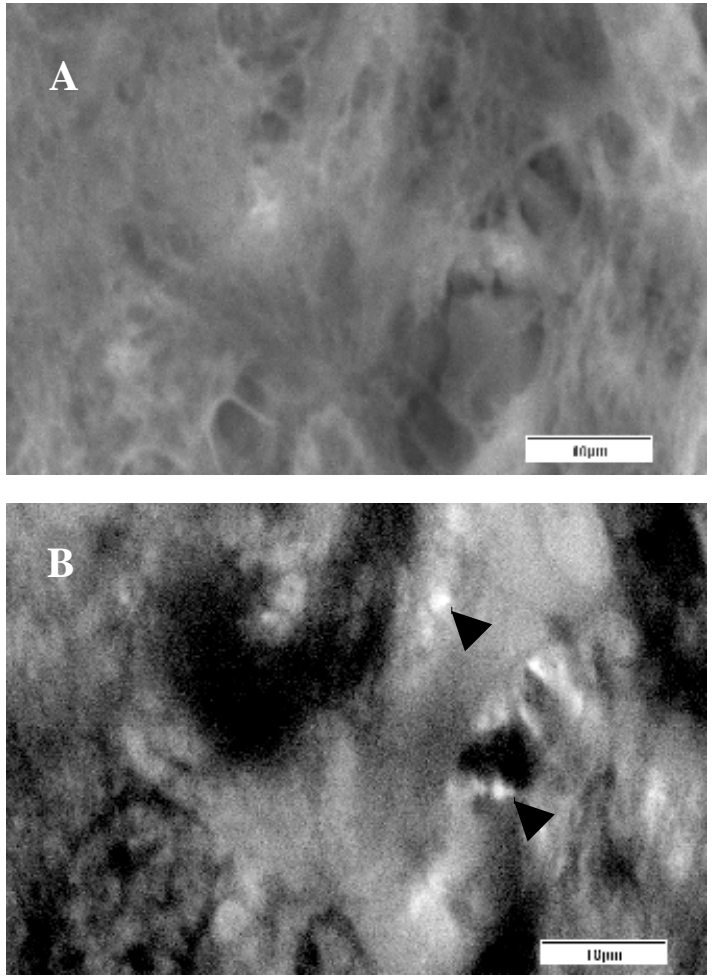

FIG. 3. A. Detail of boxed area in fig. 2 . B. Several -ve BEI-positive particles are identified in the cytoplasm of a multinucleate giant cell (arrowheads) (original magnification x 4,500).

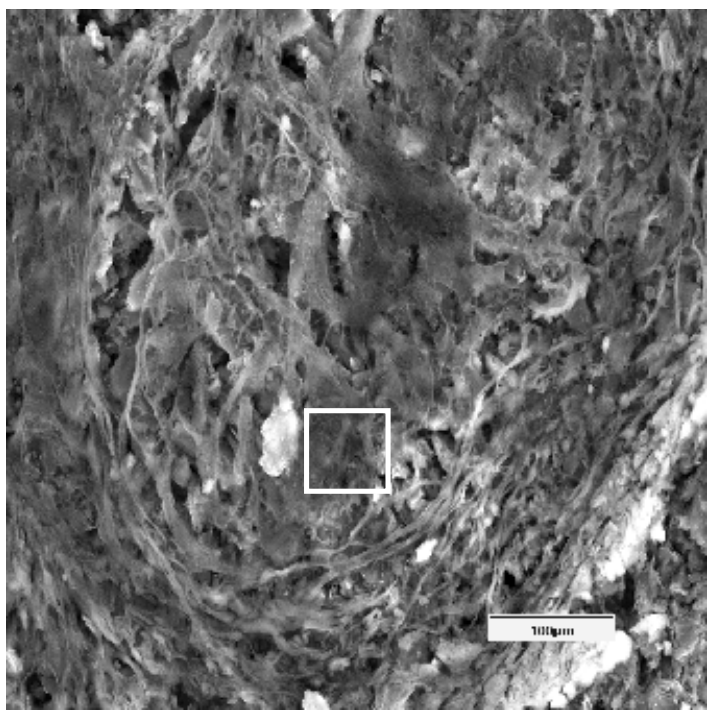

FIG. 2. Secondary electron image of multinucleate giant cells (original magnification $\mathrm{x} 450$ ).
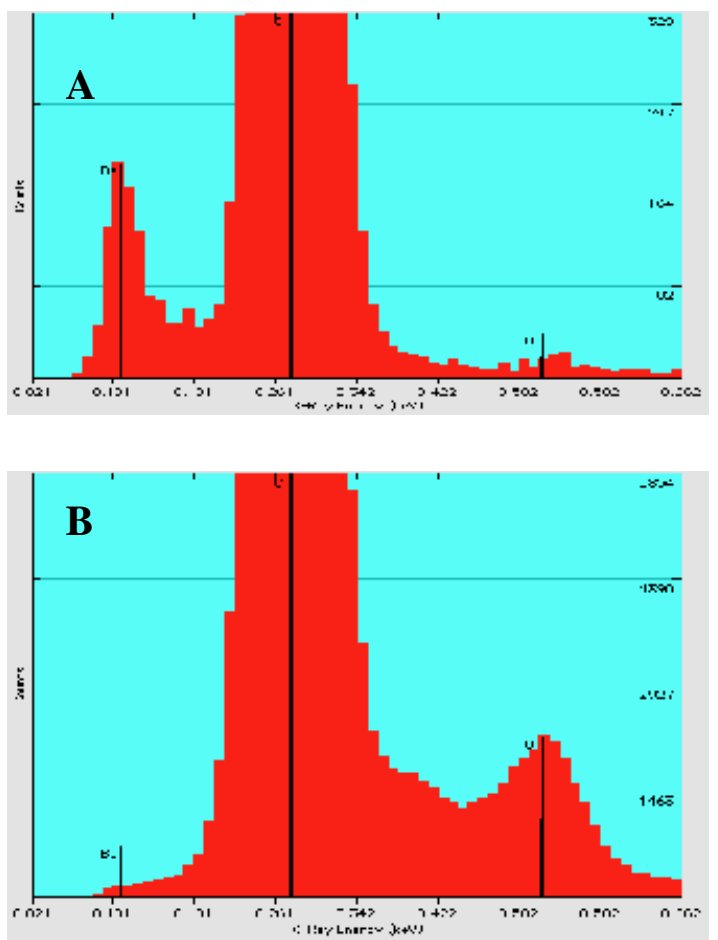

FIG. 4. A. Energy dispersive x-ray analysis spectrum of an intracytoplasmic backscatter-positive particle with discrete peaks for beryllium (Be). B. Spectrum from area away from particle shows background level of $\mathrm{Be}$ and a peak for oxygen $(\mathrm{O})$. 